\title{
Double Gallbladder Diagnosed by T-tube Cholangiogram
}

\author{
Major S M Milner \\ BDS, FRCS(Ed), RAMC*, Senior Specialist in Surgery \\ Squadron Leader I E Hawthorn \\ FRCS(Ed), RAF, Senior Specialist in Surgery
}

Department of Surgery, Princess Alexandra Hospital Wroughton, Royal Air Force Wroughton, Swindon, Wilts SN $40 Q \mathrm{~J}$

\section{Introduction}

Double gallbladder is a rare congenital abnormality, usually diagnosed during the pre-operative assessment of gallbladder disease. We present a case where ultrasonography, oral cholecystography and per-operative cholangiography failed to demonstrate a second gallbladder. The diagnosis was eventually made at T-tube cholangiography.

\section{Case Report}

A 57 year old man was admitted for cholecystectomy because of recurrent biliary colic. A pre-operative oral cholecystogram showed a non-functioning gallbladder and an ultrasound scan revealed multiple gallstones. At operation a large gallbladder full of stones was found, surrounded by dense inflammatory adhesions. A per-operative cholangiogram revealed a bile duct of normal calibre with a filling defect in its distal third (Fig 1). The common bile duct was explored and a good view of the ampulla of Vater was seen at choledochoscopy. Just lateral to this a second small opening was present and this was thought to be the entry of the pancrcatic duct. The common bile duct was closed over a T-tube. A subsequent T-tube cholangiogram at ten days demonstrated no residual stones, but a separate small gallbladder was seen to arise by a duct which joined the common duct in its ampullary portion (Fig 2). The patient made an uneventful recovery and remains symptom free after onc year.

\section{Discussion}

Two hundred cases of double gallbladder have been reported in the literature and all of these were removed for chronic inflammation and/or gallstones ${ }^{1}$. No case, however, has presented at T-tube cholangiography where pre-operative and postoperative investigations failed to demonstrate the abnormality. Although choledochoscopy allowed clear visualization of the opening of the second duct, this was thought to be a pancreatic duct abnormality because this occurs much more frequently. ${ }^{2}$

*Now, Queen Elizabeth Military Hospital, Stadium Road, Woolwich SE184QH
Although it may well cause symptoms in the future, the extra gallbladder was not removed because of the late presentation. A second cholecystectomy may be indicated later.

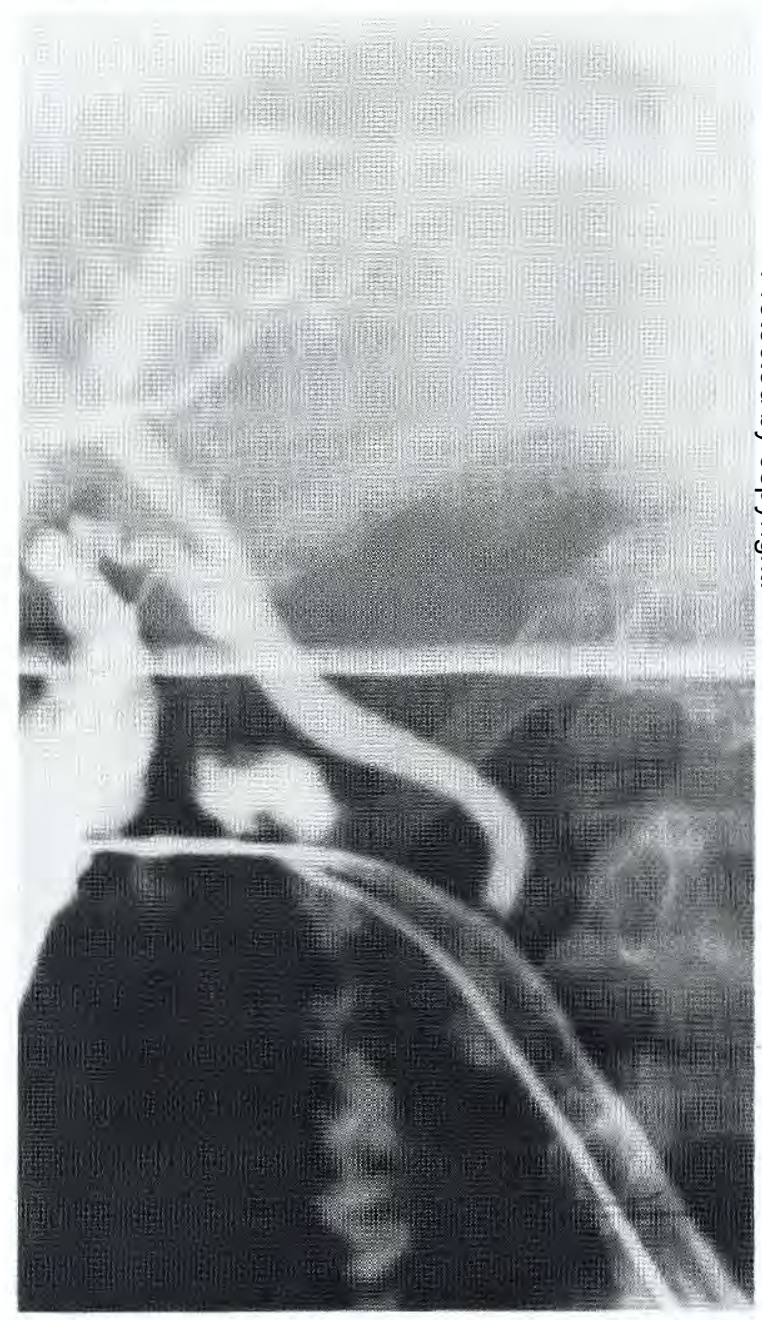

Fig 1. Per-operative cholangiogram showing a bile duct of normal calibre with a filling defect at the lower end. The second gallbladder cannot be seen. 


\section{Acknowledgement}

The authors wish to express their gratitude to Group Captain Mahoney for permission to report on his patient.

\section{REFERENCES}

1. Ritchie A W S and Crucioli V. Double Gall Bladder with cholecystocolic fistula; A case report. Br J Surg 1980; 67: 145-146,

2. Anderson J E, Ed. Grant's Atlas of Anatomy. 8th ed. Baltimore: Williams and Wilkins, 1983. 2-90.
Fig 2. T-tube cholangiogram taken 10 days post-operatively. The second gallbladder is demonstrated.

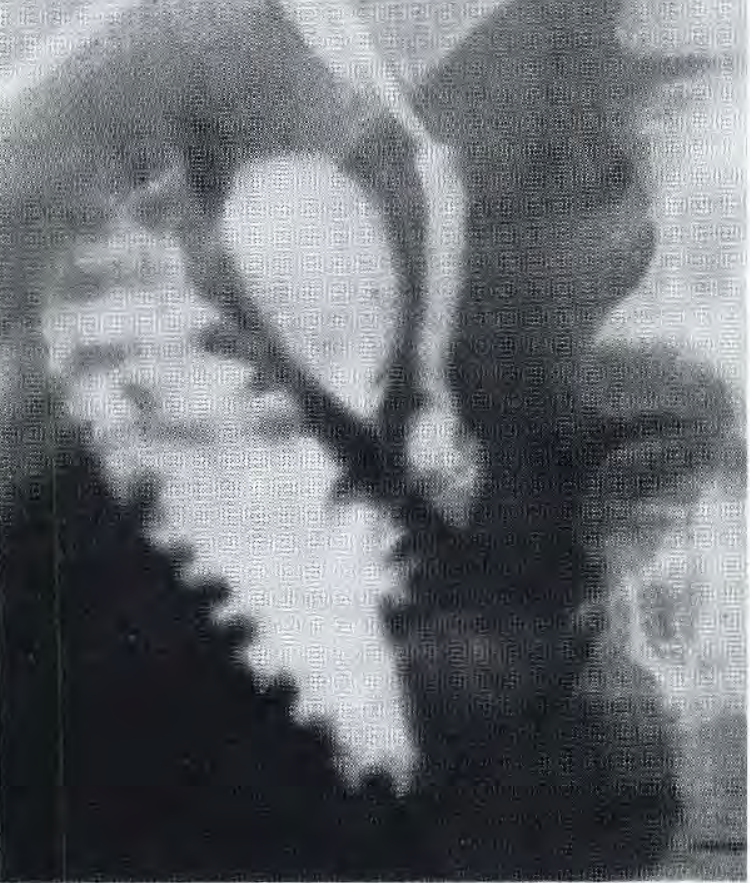
Batimore: Willias and Wilkins, 1983. 2.90. 